\title{
MAPAS DEL OTRO MUNDO. PANORÁMICA SOBRE
LOS TEXTOS ÓRFICOS
}

Javier Martínez Villarroya*

RESUMEN: A pesar de que muchas veces hemos oído hablar sobre orfismo, una pátina de confusión empaña nuestros conocimientos. Parte de ese desconcierto es inevitable: para adentrarse en el misterio, no hay camino (no hay método). Sin embargo, ¿es posible encontrar un bastón que nos ayude a caminar en la noche oscura del mito? Aquí, presentamos una somera y rigurosa introducción al orfismo y un par de hipótesis: el alma lograba escapar de la cadena de las reencarnaciones por el décalage que órficos y pitagóricos veían en las razones musicales, astronómicas y matemáticas; su destino final era su origen: la vasija de las almas o pensamiento cósmico.

শ্ৰ

ABSTRACT: Although we may have heard of Orphism, however confusion obscures our understanding of it. Most of it is unavoidable since there is no established path or method to explore the mystery. Yet, is it possible to find a cane to aid us walking through the dark night of the myth? In this article, a brief yet rigorous introduction to Orphism will be presented along with a couple of conjectures namely, that the soul was able to escape from the chain of reincarnations by means of décalage which Orphics and Pythorageans attributed to musical, astronomical, and mathematical proportions. Its final destination was its origin: the jar of souls or cosmic thought.

PALABRAS ClAVE: Textos órficos, transmigración de las almas, origen del mundo, viaje al más allá, mitología griega.

KEY WORDS: Orphic texts, transmigration of souls, the world's origin, journey to the underworld, Greek mythology.

RECEPCIÓN: 14 de febrero de 2013.

APROBACIÓN: $1^{\circ}$ de marzo de 2013.

* Departamento Académico de Lenguas, ITAM. 
CITAM Derechos Reservados.

La reproducción total o parcial de este artículo se podrá hacer si el ITAM otorga la autorización previamente por escrito. 


\section{MAPAS DEL OTRO \\ MUNDO. \\ PANORÁMICA SOBRE LOS TEXTOS ÓRFICOS}

\section{¿Quién fue Orfeo?}

\section{Preguntarnos por la figura de Orfeo} es, sin lugar a dudas, legítimo; tratar de responder en tan pocas páginas es, como mínimo, una locura. El personaje aparece por doquier en la literatura y música occidentales y, sin embargo, poco sabemos de su origen. Nos remite a un personaje que desborda la figura apolínea en la que se le encasilló durante el medievo y la época moderna: aquella que ha predominado en óperas y cuadros. Orfeo fue algo más que el paradigma de la armonía, el orden y la belleza. Del mismo modo que no es posible entender Grecia sin percatarnos de la etimología compartida por el orden (cosmos) y la belleza (de donde viene cosmético), o por la compartida por lo natural y lo esencial (ambos conceptos designados con la palabra phýsis), ${ }^{1}$ no es posible entender la figura de Orfeo sin recuperar su origen oscuro, instintivo, visceral y chamánico. En este sentido, desde hace algunos años, existe una nueva disciplina llamada Tracología que estudia la figura de Orfeo desde una nueva óptica: valora su origen tracio y sus características dionisíacas.

Orfeo fue miembro de la expedición de los argonautas, contemporáneo de Hércules, Jasón, Cástor, etc., con quienes navegó más allá de las Simplégades -las Piedras Entrechocantes- en busca del vellocino

${ }^{1}$ M. Heidegger, "On the essence and concept of phýsis in Aristotle's Physics B, 1", en Heidegger, Pathmarks, 1998, Cambridge and New York, Cambridge University Press, pp. 183-230. 
de oro. En la aventura, Orfeo fue providencial: su ritmo era el que seguían los remeros y su canto logró derrotar al de las sirenas. La nave Argos alcanzó la lejana Cólquida y Jasón consiguió el vellocino de oro. Desde el descubrimiento de la civilización micénica por Schliemann (a finales del siglo XIX), se considera que la guerra de Troya acaeció hacia el 1200 a. C. Consecuentemente, si los héroes de la nave Argos tienen su origen en personajes reales, éstos debieron existir un poco antes de esta fecha: según las fuentes clásicas, Hércules fue una generación anterior a Agamenón. Así pues, si existió un personaje "real" que inspiró el mito de Orfeo, podría haber existido en el siglo XIII a. C.

El canto de Orfeo fue proverbial. No sólo derrotó a las sirenas en el Mediterráneo oriental, sino que también amansó fieras e incluso movió árboles y rocas. En realidad, Orfeo fue un "maestro de verdad":2 su canto, su palabra, "instauraba realidad". ¿Qué significa esto? La palabra griega que traducimos por verdad ( $\dot{\alpha} \lambda \hat{\eta} \theta \varepsilon ı \alpha$, de la cual proviene el nombre propio "Alicia"), está compuesta por el prefijo privativo "a" (el mismo de "a-simétrico" o "a-normal"), un lexema perteneciente al campo del olvido (leth, de donde derivan lutháno - hacer olvidary Lete -río del inframundo cuya agua hacía olvidar-) y una desinencia verbal que marca participio de presente (en español inexistente como forma verbal, pero existente como nombre: estudiante, amante, “comiente"). ${ }^{4}$ Por lo dicho, en la Grecia micénica lo verdadero no era algo claro, fácilmente reconocible y opuesto a lo falso. Por el contrario, lo verdadero era algo que se arrancaba de las garras del olvido. ${ }^{5}$ Así pues, en Grecia la verdad era desvelamiento, y la mentira, un "pliegue" de la verdad. ${ }^{6}$ La prehistoria de la palabra verdad nos hunde en un sistema de pensamiento que en la Grecia clásica ya casi había

${ }^{2}$ M. Detienne, Los Maestros de Verdad en la Grecia Arcaica, 1986, Madrid, Taurus.

${ }^{3}$ Utilizando la terminología de los lingüistas, diríamos que muchos de los enunciados que en boca de personas ordinarias son "representativos", en boca de un chamán (como es el caso de Orfeo) son "realizativos".

${ }^{4}$ M. Heidegger, El Ser y El Tiempo, 1973, Madrid, FCE.

${ }^{5}$ Durand afirma que la luz es siempre arrancándose de las tinieblas, mientras que las tinieblas no necesitan de la luz para existir (cfr. G. Durand, Las estructuras antropológicas del imaginario, Introducción a la arquetipología fundamental, 2004, México, FCE).

${ }^{6}$ En palabras de Detienne, "La negatividad no queda aislada, colocada aparte del Ser; constituye un pliegue de la "verdad"' (op. cit., p. 59). 
desaparecido: el del adivino, el poeta y el rey justo. Según M. Parry, las sociedades orales como la micénica se caracterizan por no tender a reconstruir el pasado desde una temporalidad lineal. Por el contrario, en ellas el poeta descifra lo invisible: "lo que es, lo que será y lo que fue". La palabra cantada es eficaz porque instituye por virtud propia un mundo simbólico religioso que es lo real mismo. ${ }^{7}$ Mientras que en la época clásica el poeta se encarga simplemente de devolverle la imagen a la aristocracia, en la sociedad micénica tiene una función litúrgica sacra: reordenar el mundo. Desde esta perspectiva, Orfeo es el chamán por antonomasia. ${ }^{8}$

Su condición de maestro de verdad es imprescindible para entender el papel que se le atribuyó en la época clásica. Por un lado, se decía que había logrado alcanzar los infiernos y describir lo que allí vio. Por otro, tras su muerte, su cabeza se dedicó a profetizar el futuro. En ambos casos, su palabra prefigura la realidad porque "la palabra oracular no es el reflejo de un acontecimiento preformado, es uno de los elementos de su realización". ${ }^{9}$ En este texto, nos interesa destacar el primero de estos dos capítulos: su descenso al inframundo.

"Pues si los hados niegan el permiso a mi esposa, tengo la certeza de que no quiero volver: gozaos con la muerte de los dos". Mientras él decía tales cosas y tañía las cuerdas que acompañaban su canto, las almas sin sangre lloraban; y Tántalo no trató de alcanzar la huidiza agua, y la rueda de Ixión se quedó parada, y las aves no desgarraron el hígado, y las Bélides desatendieron sus vasijas, y te sentaste en tu roca, Sísifo. Se dice que entonces por primera vez las mejillas de las Euménides, doblegadas por el canto, se humedecieron de lágrimas, y ni la real esposa ni el que gobierna las profundidades son capaces de decir que no al que suplica y llaman a Eurídice. Estaba ella entre las sombras recientes y avanzó con un paso lento a causa de la herida. El rodopeo Orfeo acogió a ésta a la vez

${ }^{7}$ Ibid, p. 32.

${ }^{8}$ J. Martínez Villarroya, "El árbol y el alma en Platón. Latencias chamánicas en la filosofía griega", en L. Romero (coord.), Chamanismo y curanderismo: nuevas perspectivas, 2011, Puebla, México, Benemérita Universidad Autónoma de Puebla, pp. 259-81.

${ }^{9}$ Detienne, op. cit, p. 59. 
que la condición de no llevar atrás sus ojos hasta salir de los valles del Averno; o habría de quedar sin valor el don. ${ }^{10}$

El final de la historia es conocido por todos: Orfeo no resiste la tentación y se da la vuelta para ver a su amante. En ese preciso momento, Eurídice retorna a las simas del Tártaro, Orfeo la pierde definitivamente y las puertas del Hades, el infierno que algunos griegos describieron como "lo que no tiene forma", se le cierran hasta el momento de su propia muerte.

\section{¿Qué escribió Orfeo?}

El alfabeto griego se desarrolló hacia el siglo IX a. C., a partir del sistema consonántico de escritura de los fenicios. Como es sabido, la gran aportación de los griegos fue dotar de signos a los sonidos vocálicos. Si Orfeo fue un personaje "real", por lo dicho, habría vivido en el siglo XIII a. C. y, consecuentemente, no podría haber escrito con el alfabeto griego; lo habría hecho con el lineal B, el sistema de escritura de la época micénica. Sin embargo, de esa época no se conservan más que algunos escritos administrativos.

La tradición órfica contaba que tanto textos griegos como romanos fueron escritos por el mismísimo Orfeo. Por supuesto, esto es "realmente" imposible porque dichos textos se escribieron en un período que abarca más de mil años. Sin embargo, lo que sí pudo hacer Orfeo fue inspirarlos o cantarlos por primera vez (en este segundo caso, la tradición oral, de generación en generación, los habría transmitido hasta su petrificación en papel).

Precisamente por la heterogeneidad de sus escritos, el "orfismo" es multiforme y variopinto, tanto en sus doctrinas como en sus apariciones en el espacio y el tiempo. Por lo dicho, la comunidad científica prefiere hablar de "textos órficos" en lugar de "orfismo", y define tales escritos simplemente como aquellos que la tradición atribuye a

${ }^{10}$ Ovidio, Metamorfosis, libro X, 38-53 (1995/2009, Madrid, Cátedra, trad. de C. Álvarez y R. M. Iglesias). 
Orfeo. Tal explicación, no obstante, amontona en un mismo saco textos dispares.

\section{Causa de la heterogeneidad de las fuentes órficas}

\begin{tabular}{|c|c|}
\hline Territorial & $\begin{array}{l}\text { Los escritos órficos (muchos de ellos encontrados en contextos arqueoló- } \\
\text { gicos) se han encontrado en lugares muy alejados (en la actual Ucrania, } \\
\text { en el sur de Italia, en la península balcánica, etc.). }\end{array}$ \\
\hline Temporal & $\begin{array}{l}\text { Los textos órficos pertenecen a épocas muy diferentes: Píndaro y Esquilo } \\
\text { transmiten algunos fragmentos ya en el siglo VI a. C.; del siglo V a. C. } \\
\text { serían los transmitidos por Aristóteles un siglo después y las partes más } \\
\text { antiguas del Papiro Derveni; mil años después, todavía se originan textos } \\
\text { que se atribuyen a Orfeo. Si aceptamos que Orfeo vivió en el siglo XIII a. C. } \\
\text { y que algunas prácticas órficas se extendieron hasta la actualidad a través } \\
\text { del cristianismo, el límite temporal de su pensamiento abarca, por lo tanto, } \\
\text { prácticamente toda la historia de Occidente. }\end{array}$ \\
\hline Temática & $\begin{array}{l}\text { Los textos tratan sobre astrología, cosmogonía, escatología, viajes épicos, } \\
\text { fórmulas mágicas, etc. }\end{array}$ \\
\hline Material & $\begin{array}{l}\text { El soporte en que están escritos los textos es muy diverso: } \\
\text { a. Pergamino (los textos transmitidos por la tradición antigua, medieval y } \\
\text { renacentista de copistas -los fragmentos órficos transmitidos por Aristó- } \\
\text { fanes, Platón, Aristóteles, etc.-) } \\
\text { b. Oro (laminillas de Hiponio, Petelia, Entella, etc.) } \\
\text { c. Hueso (huesos inscritos de Olbia Póntica) } \\
\text { d. Papiro (Papiro de Derveni). }\end{array}$ \\
\hline
\end{tabular}

Por lo mencionado, y aunque se sigan encontrando rasgos comunes en los diversos textos, últimamente nadie en la comunidad científica defiende una "identidad órfica" análoga a la que pudieron tener otros movimientos de la antigua Grecia mucho más homogéneos, como por ejemplo, el epicureísmo.

\section{¿Desde dónde estudiamos a los órficos?}

Para responder a la pregunta de quiénes fueron los órficos, primero es necesario aclarar desde dónde lo hacemos. ${ }^{11}$ Durante el siglo XIX, los

${ }^{11}$ Nos basamos principalmente en A. Bernabé, "Tendencias recientes en el estudio del orfismo", Ilu Revista de Ciencias de las Religiones, 1995, núm. 0, pp. 23-32; y M. A. Santamaría Álvarez, "Orfeo y el orfismo. Actualización bibliográfica", Ilu Revista de Ciencias de las Religiones, 2006, 
estudiosos del mundo griego se enzarzaron en una polémica importante: ¿existió en la antigua Hélade una religión "superior" a la "simple" de los poemas homéricos?; y, en consecuencia, ¿la creencia en la inmortalidad del alma en Grecia es anterior a Platón? Entonces, la figura de Orfeo dejó de ser monopolio de la ópera y se convirtió en el centro de la polémica. ¿Fue Orfeo el profeta de una religión, paralela en el tiempo a la homérica que, sin embargo, defendía creencias que encontramos luego en el cristianismo?

Los trabajos sobre orfismo más importantes del siglo XIX son los de Creuzer, Hermann, Lobeck, Bachofen, Nietzsche, Rohde, Dieterich, Harrison, Diels y Rohde. Analizando sus escritos, Burkert concluye que la literatura en torno a Orfeo fue un vaivén entre dos tendencias: una "racionalista" y otra "mística". ${ }^{12}$ Creuzer, Kern, Bachofen, Nietzche y Rohde son, probablemente, los representantes más importantes de la segunda. ${ }^{13}$ Ya no interpretan el orfismo, a diferencia de lo que se acostumbraba, como una religión "superior", apolínea, racional y luminosa; por el contrario, recuperan su sentido más visceral, telúrico y demoníaco. A partir de los años treinta, hubo una reacción contra esta tendencia. La encabezó Willamowitz, quien no aceptaba el enfoque de Kern, editor de referencia entonces (y todavía hoy) de los textos órficos. Entre los estudiosos de esta línea crítica destacan Linforth, Dodds, Zuntz y Moulinier. Desde los años cincuenta a los ochenta del siglo XX, las posiciones hipercríticas fueron las dominantes, pero a partir de entonces ha ido ganando fuerza una posición intermedia entra la tendencias "mística" y "racionalista" y, por ello, se han recuperado trabajos clarividentes como los de Guthrie o Nilsson.

Ambas modas historiográficas son hijas de su tiempo. La tendencia mística, que dura hasta los años treinta del siglo $\mathrm{xx}$, debe entenderse como manifestación tardía del romanticismo y se caracteriza por

núm. 8, pp. 225-64. Anteriormente Bernabé había ya tratado el tema: A. Bernabé, “La poesía órfica: un capítulo reencontrado de la literatura órfica”, Tempus, 1992, núm. 0, pp. 5-41.

${ }^{12} \mathrm{~W}$. Burkert, De Homero a los Magos, la tradición oriental en la cultura griega, 2002, Barcelona, El Acantilado.

${ }^{13}$ Nietzsche, El Nacimiento de la Tragedia, 1973, Madrid, Alianza; J.J. Bachofen, Mitología arcaica y derecho materno, 1998, Barcelona, ed. Anthropos; Rodhe, Psyché, la idea del alma entre los griegos, 2006, México, FCE. 
combinar lo apolíneo de Orfeo con la autenticidad romántica de Dioniso, el dios regente en lugar de Zeus según los órficos. Por el otro lado, las posturas hipercríticas deben entenderse en conexión con el marxismo imperante en la mayoría de las universidades europeas desde los años treinta del siglo XX. Tal paradigma se alarga hasta los ochenta como consecuencia del proceso de "desencantamiento" derivado de la Segunda guerra mundial, que es una réplica contra la propuesta unidireccional de mitificación del mundo del nacionalsocialismo. En el orfismo, esta tendencia se manifiesta en tesis que retrasan las dataciones de los documentos y minimizan su importancia y extensión.

A diferencia de otras corrientes de la Antigüedad, cuyo corpus conservado se debe casi exclusivamente a la tradición copista, el orfismo posee un importante acervo de naturaleza arqueológica. Por lo mismo, su estudio no sólo ha dependido de las tendencias historiográficas del momento: algunos descubrimientos, como el del Papiro Derveni y el de las láminas inscritas en hueso de Olbia Póntica, obligaron a replantear hipótesis hasta entonces tomadas como ciertas. En otras palabras: revolucionaron los estudios sobre orfismo. Tales descubrimientos han hecho que emerjan incluso nuevas disciplinas, como la llamada "Tracología" (especialmente importante en Bulgaria) y que se dedica a estudiar el orfismo desde sus raíces tracias.

En la actualidad, los estudiosos más destacados pertenecen, de un modo u otro, a alguna de estas tres tendencias. Luc Brisson, canadiense afincado en Francia, sigue la tradición clásica anterior al descubrimiento de Derveni; retarda notablemente el orfismo e interpreta gran parte de los textos como si se derivasen del culto a Mitra, que se extendió por el Mediterráneo sobre todo a partir del siglo I d. C. Así, por ejemplo, considera que la figura de "El Tiempo" de las Rapsodias es deudora de la de Mitra y que, por lo tanto, tan importante dios en el panteón órfico no pudo existir hasta antes del imperio romano. Asimismo, enfatiza la importancia del neoplatonismo en la composición de gran parte de los textos órficos. Por el contrario, Burkert $\mathrm{y}$, sobre todo, West envejecen el orfismo y lo consideran una tradición más o menos estable desde mucho antes. Fundamentan su hipótesis recurriendo, además de a la filología, a la historia: durante el periodo orientali- 
zante (finales del siglo VIII a. C. y el siglo VII a. C.), no sólo la cerámica griega introdujo elementos próximo-orientales (especialmente fenicios); también la arquitectura, la filosofía y la religión hicieron lo propio. West, sin embargo, da un paso más allá y postula un importante sustrato oriental en el imaginario griego, muy anterior al fenicio y, consecuentemente, promueve el estudio de los mitos griegos en relación con los indios, iranios, hititas, hurritas y babilonios. En este sentido, encuentra los precedentes de la castración de Uranos por Cronos en Oriente. Entre ambas perspectivas de estudio del orfismo se encuentra la de Alberto Bernabé y sus colaboradores: aferrándose principalmente a los textos (a diferencia de West, cuya visión de la historia recurre en mayor medida a la arqueología), aceptan influencias orientales y cierto movimiento más o menos homogéneo que podría denominarse orfismo en etapas tempranas del mundo griego.

Además de estas posturas, que son las principales en el estudio del orfismo, existen otras enfocadas en la historia antigua en general, que son notablemente más radicales que las aceptadas por la filología. Ésta, porque tiende a ceñirse a los textos e infravalorar otros registros arqueológicos, es más lenta en sus cambios de paradigma que su ciencia hermana la historia. En este sentido, es importante destacar los estudios de Martin Bernal por la repercusión que han tenido. ${ }^{14}$ Su hipótesis fundamental es que la historiografía clásica ha menospreciado sistemáticamente el sustrato semítico y africano de la cultura griega. Para él, la razón es clara: el paradigma ario predominante en Europa desde el siglo XVII hasta la Segunda guerra mundial buscaba los orígenes de la cultura occidental en "lo indoeuropeo"; cualquier otra veta de investigación se obviaba. El racismo (consciente o inconsciente), extendido principalmente en Gran Bretaña y Alemania, hacía impensable que la civilización occidental derivase de la de los negros o judíos. En consecuencia, Bernal invita a repensar la historia contemplando hipótesis de trabajo hasta ahora inexploradas. Por ejemplo, para él, el Egipto faraónico tuvo su origen en el Alto Egipto, el Egipto negro, el de Sudán, y no en Mesopotamia. Del mismo modo, indica la necesidad

${ }^{14}$ M. Bernal, Atenea negra. Las raíces afroasiática de la civilización clásica, 1993, Barcelona, Crítica. 
de estudiar seriamente y a conciencia las relaciones entre los mitos africanos, los próximo-orientales y los griegos. Según Bernal, un 20-25\% del léxico griego (fundamentalmente topónimos y nombres de dioses) es egipcio. Los préstamos se debieron de dar entre el 2100 y el 1100 a.C. En tal caso, debe contemplarse también un posible origen egipcio para el orfismo (habría indicios para hacerlo: en Egipto se creía en la inmortalidad del alma; tanto Dioniso como Osiris fueron descuartizados; ambos dioses eran honrados en cultos mistéricos; un amplio número de testimonios afirman que Orfeo importó los misterios desde Egipto-especialmente importantes son los transmitidos por Diodoro Sículo). ${ }^{15}$ A pesar de las diferencias entre escuelas, Bernabé identifica ciertos puntos en los que coinciden la mayoría de investigadores: ${ }^{16}$

1) La mayoría de trabajos se centra en temas concretos; hay muy pocas obras que den una panorámica global.

2) Se incide más en lo literario que en lo religioso; los que se centraron en el aspecto religioso lo hicieron hace mucho: Nilsson (1935), Guthrie (1935), Prümm (1956) y Bianchi (1957).

3) Se valoran y aceptan como verídicos los fragmentos transmitidos por autores como Damascio, Proclo o Platón.

4) A pesar del carácter multiforme y a menudo impreciso de su pensamiento, y de la diversidad de variantes según la época y el lugar, es posible identificar algunas creencias generales.

\section{¿Quiénes fueron los órficos?}

Ante la variedad de propuestas historiográficas, el mismo Bernabé da una útil definición de lo que es el orfismo:

Llamamos orfismo a un movimiento religioso, o mejor sería decir una forma peculiar de practicar la religión griega basada en los preceptos de

${ }^{15}$ San Cristóbal Jiménez, "La transmisión de ritos”, en A. Bernabé y F. Casadesús (coords.), Orfeo y la tradición órfica, 2008, Madrid, Akal, pp. 91-104.

${ }^{16}$ Aunque es más antiguo que otros estados de la cuestión (Bernabé, op. cit., 1995), sus conclusiones continúan vigentes. 
una amplia y variada literatura pseudepigráfica atribuida a Orfeo. Como es sabido (y en más de un autor, discutido), uno de sus rasgos más originales es una explicación del origen del hombre, en la que se incardina una serie de creencias sobre el alma. Se cuenta en las teogonías órficas que los Titanes, dioses primigenios y malvados, mataron y devoraron a Dioniso y por ello Zeus los fulminó. De sus cenizas se originaron los seres humanos, razón por la cual tenemos un doble componente: una parte malvada, díscola y violenta, que es la heredada de los titanes, y otra positiva, que procede de la parte de Dioniso ingerida por sus devoradores. Para los seguidores del Orfismo, el alma es inmortal, pero debe transmigrar y encarnarse en diversos cuerpos mortales en expiación del antiguo delito cometido por los Titanes. Para que el alma pueda escapar definitivamente del ciclo de las reencarnaciones y alcanzar una vida feliz en el otro mundo, debe someterse a determinadas prácticas, básicamente una iniciación, en que se alcanza una especie de éxtasis, una vida ascética en la que deben observarse ciertos tabúes rituales (no llevar vestidos de lana, no derramar sangre, no comer carne) y determinados conocimientos sobre el origen del mundo y el destino del alma para orientarse por el más allá. ${ }^{17}$

Cada uno de estos rasgos está apoyado en algún texto. Por ejemplo, su carácter mistérico queda patente en sentencias como las que siguen: "Cantaré para conocedores; cerrad las puertas, profanos. Hablaré a quienes es lícito, cerrad las puertas profanos"; ${ }^{18}$ "Me dirijo a los sensatos que poseen un corazón limpio y obediente a los inmortales; a los necios la ley divina no les permite encontrar una ayuda inalterable". ${ }^{19} \mathrm{El}$ orfismo comparte el carácter mistérico con el dionisismo, el pitagorismo, los misterios de Eleusis y los de Samotracia. Todos estos movimientos, de límites difusos entre sí, eran secretos, realizaban rituales escatológicos e iniciáticos, creían en el renacimiento del ser humano, etc. No se

${ }^{17}$ A. Bernabé, "Elementos orientales en el orfismo” en J.L. Cunchillos, J. M. Galán, J.A. Zamora, S. Villanueva de Azcona (eds.), Actas del Congreso "El Mediterráneo en la Antigüedad: Oriente y Occidente”, 1998, Sapanu. Publicaciones en Internet II.

${ }^{18}$ Fr. 1 . Los fragmentos 3, 19, 58, 74, 101, 337, 378, etc., dicen más o menos lo mismo. En todo este artículo, si no se dice lo contrario, utilizamos la traducción y numeración de los fragmentos órficos de A. Bernabé, Hieros Logos. Poesía órfica sobre los dioses, el alma y el más allá, 2003, Madrid, Akal.

${ }^{19}$ Lapidario Órfico, 5-7 (traducción de Opiano Calvo Delcán, De la caza, De la pesca. Anónimo, Lapidario órfico, 1990, Madrid, Gredos). 
ha conservado ningún testimonio claro de lo que en tales ritos sucedía precisamente porque su divulgación era penada. A Esquilo, nacido en Eleusis, se le acusó (aunque luego se le absolvió) de haber revelado los misterios. En Las Bacantes de Eurípides, las ménades decapitan a Penteo por haberlas espiado en sus ritos exclusivos. Este tipo de muertes es constante en los ámbitos órfico-dionisíacos. El propio Orfeo fue desmembrado por las ménades, y Dioniso, el rey de los dioses, por los titanes.

Mas no tuvo (Dioniso) por mucho tiempo el trono de Zeus, sino que los Titanes, tras haberse untado con astuto yeso el engañoso óvalo del rostro, lo mataron, por causa de la ira de la diosa desalmada, la rencorosa Hera, con un cuchillo del Tártaro mientras observaba la imagen falsa del espejo que era su contrafigura. ${ }^{20}$

Hace tiempo que los teólogos han convertido el espejo en el símbolo de la capacidad del universo para llenarse con el intelecto. Por eso dicen que Hefesto fabricó un espejo para Dioniso y que cuando el dios se miró y vio su imagen emprendió la creación de todo lo particular. ${ }^{21}$

Los Titanes, tras haber desmembrado a Dioniso, se lo sirvieron a Apolo, su hermano, echándolo en una caldera y él la puso cerca del trípode. ${ }^{22}$

El desmembramiento ritual del rey es común en culturas de carácter chamánico. En el caso que nos concierne, hay diversos datos importantes: como mínimo desde el 500 a. C., los órficos de Olbia Póntica usaban espejos rituales; ${ }^{23}$ al respecto, West defiende que poseer la imagen de alguien en un espejo equivale a tener a esta persona bajo tu poder, ${ }^{24}$ y que los titanes probablemente eran manifestaciones de los ancestros ${ }^{25}$ además, según Detienne, el mito de los titanes puede tener un origen pseudoetimológico, dado que titanos en griego significa yeso y también cal viva; finalmente, Eliade menciona ceremonias de sociedades secre-

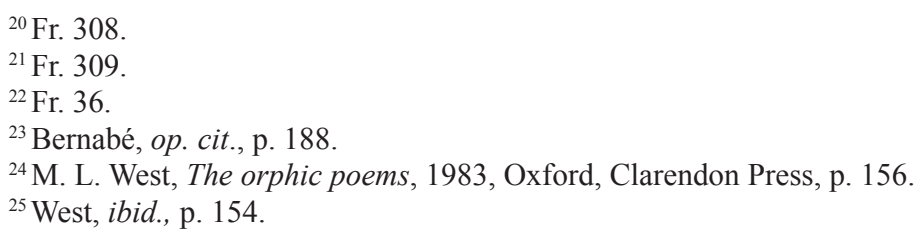


tas de lugares lejanos a Grecia en las cuales los iniciados se pintaban el rostro y el cuerpo entero con ceniza para descender a los infiernos e, igualmente, sufrían palizas e incluso amputaciones. ${ }^{26}$

Por lo dicho, es más que legítimo sospechar que en Grecia hubo un culto chamánico que en la época clásica, al menos como reminiscencia, todavía pervivía. En el dionisismo, especialmente el vinculado a Tracia, Orfeo y Dioniso debieron de ser figuras divinas cuyas penurias eran repetidas una y otra vez por los sacerdotes que los honraban. Todo chamán en el sentido tradicional, cuando inicia su viaje, es destrozado como lo es el cosmos que lo rodea. Sin esta condición -la destrucciónsería imposible la recreación del mundo, la de sí mismo o la del paciente que tiene a su cargo. En otras palabras: para renacer es necesario morir; la muerte es condición para que haya vida.

Una vez engañado, los titanes desgarran a Dioniso y se lo comen. Zeus, padre de Dioniso y de quien va a heredar el trono del mundo, se venga desintegrándolos con el rayo. De sus gotas de sangre, o de sus cenizas, nacemos los humanos. Deméter, la madre tierra, recoge los pedazos y revive al dios niño.

(I) Irritado contra ellos Zeus los fulminó con el rayo y del residuo de los vapores emitidos por ellos se produjo la materia de la que nacieron los hombres. Por eso está prohibido suicidarse [...] porque nuestro cuerpo es de Dioniso, ya que somos de hecho una parte de él, si estamos conformados por el residuo de los Titanes que comieron su carne. (III) Los hombres todos, procedemos de la sangre de los Titanes. (IV) Cuando Zeus organizó todo, la raza de los hombres nació de las gotas de sangre sagrada caídas del cielo. ${ }^{27}$

Por nuestro origen, tenemos una naturaleza doble: diabólica (lo que tenemos de los titanes) y divina (lo que tenemos de Dioniso). Por la primera, estamos condenados a vivir encarcelados en un cuerpo. Por la segunda, aspiramos a liberarnos del castigo del ciclo de las rencarnaciones.

(I) Las personas estamos en una especie de reclusión. [...] (III) Todos los hombres somos de la sangre de los titanes, así que como aquéllos son

${ }^{26}$ M. Eliade, El Chamanismo y las técnicas arcaicas del éxtasis, 1976, México, FCE, p. 69.

${ }^{27}$ Fr. 320. 
enemigos de los dioses y lucharon contra ellos, tampoco nosotros somos amigos suyos, sino que somos mortificados por ellos y nacemos para ser castigados, permaneciendo bajo custodia en la vida durante tanto tiempo como cada uno vive, y los que morimos tras haber sido ya suficientemente castigados nos vemos liberados y escapamos. El lugar que llamamos mundo es una cárcel penosa y sofocante preparada por los dioses. ${ }^{28}$

(I) Este cuerpo es sepultura del alma [...] y por otra parte, como el alma manifiesta lo que manifiesta a través de él, también en este sentido se le llama correctamente "signo". (II) Nosotros en realidad quizás estamos muertos. (III) En cumplimiento de cierto castigo el alma está uncida al cuerpo y está enterrada en él como en una sepultura. ${ }^{29}$

(IV) ¿Quién al ver esto se consideraría feliz y afortunado, si, como dicen los que pronuncian los misterios, desde el primer momento nuestra naturaleza fue constituida como si estuviera destinada a un castigo? Pues eso es lo que de una forma divina proclaman los más antiguos, cuando dicen que el alma paga un castigo y que nosotros vivimos para expiar los mayores crímenes. Pues la unión del alma con el cuerpo recuerda algo de este tipo. Es así, dicen, como entre los tirrenos torturan a muchos de sus prisioneros. Atan vivos a cada uno de ellos cara a cara y miembro a miembro con un cadáver. De igual modo el alma parece haberse estirado y unido a todos los órganos sensibles del cuerpo. ${ }^{30}$

Las almas están encerradas en el cuerpo como los prisioneros a quienes ataban vivos, miembro a miembro, a un muerto. Esta idea, que evidentemente tiene vínculos importantes con el platonismo y el cristianismo, recuerda las doctrinas cátaras medievales por su plasticidad. ${ }^{31}$ Los cátaros, que se extendieron especialmente por Occitania entre mediados del siglo XII y finales del XIII, consideraban que el mundo visible y "real" no había sido hecho por el Dios bueno y celestial. Al contario, el diablo, para reírse de Dios imitándolo, creó este mundo y encerró en él a los ángeles del Dios verdadero, nuestras almas. Por eso los cátaros buscaban la catarsis o "purificación”, es decir, lograr

${ }^{28}$ Fr. 429.

${ }^{29}$ Fr. 430.

${ }^{30}$ Ibidem.

31 “El libro de los dos principios", en F. Zambón, (ed.), El legado secreto de los cátaros, 1997, Madrid, Siruela. Para el concepto de "Dios extranjero" véanse, por ejemplo, las pp. 17 y 100. 
salir limpios de este mundo. En el caso órfico, las almas deben expiar la culpa heredada de los titanes, y por eso deben vagar de cuerpo en cuerpo.

Por tal motivo, Platón atribuye los mil años a las almas sometidas a Plutón. En cuanto a Orfeo, las lleva durante trescientos años desde los lugares subterráneos y las prisiones, de allí a su génesis, y hace de las tres centurias el símbolo del período completo de la purificación de las almas humanas, de acuerdo con el modo en que han vivido durante su tránsito por la génesis. ${ }^{32}$

Contra la religión olímpica, la órfica creía en la rencarnación y la supervivencia del alma tras la muerte terrenal. Este motivo fundamental y la concepción que tenían del otro mundo explican ciertas prácticas órficas y pitagóricas.

Aristóteles dice, en su obra Sobre los Pitagóricos, que Pitágoras prescribió la abstención de habas, o porque eran parecidas a las parte pudendas, o porque se parecían a las puertas del Hades (pues esta es la única planta que no tiene ángulos), o porque son destructoras, o porque son similares a la naturaleza del universo, o porque son oligárquicas (pues se usan en la elección del gobernante a sorteo). ${ }^{33}$

Al menos a los santuarios (sc., los egipcios) no se llevan ropas de lana ni se entierran con ellas. Pues no es lícito religiosamente. Y en ello coinciden con los llamados ritos órficos y báquicos, que son egipcios y pitagóricos. Pues no es lícito que quien participe de estos ritos sea enterrado con vestidos de lana. $\mathrm{Y}$ en torno a esto se cuenta una historia sagrada. ${ }^{34}$

Según algunos órficos, el mundo comenzó con un gran huevo cósmico, lo que explicaría otra prohibición entre ellos, a saber, la de comer huevo. ${ }^{35}$ Respecto al vegetarianismo, Marcel Detienne lo explica en función de la relación con lo divino que implican los diferentes tipos de sacri-

${ }^{32}$ Fr. 346.

${ }^{33}$ DK 58 c 3, G. S. Kirk, J. E. Raven, Schofield, M., Los filósofos presocráticos, 1987, Madrid, Gredos, traducción española de Jesús García Fernández.

${ }^{34}$ Herodoto, 2.81, traducción extraída de A. Bernabé y F. Casadesús (coord.), Orfeo y la tradición órfica, un reencuentro, 2008, Madrid, Akal, p. 703.

${ }^{35}$ M. Eliade, Tratado de Historia de las Religiones, 1972, México, Era, p. 371. 
ficios. ${ }^{36}$ Menciona dos interpretaciones opuestas de los hábitos alimenticios pitagóricos: por un lado, Timeo dice que los pitagóricos eran vegetarianos porque adoraban el altar délico "Apolo Genétor", en el que no podía ser sacrificada ninguna víctima animal; por otro, Aristoxeno de Tarento afirma que los pitagóricos comían carne de los animales aptos para ser sacrificados y comestibles. Este debate lo encarnan Pitágoras, que se alimentaba de extrañas substancias que le quitaban el hambre y la sed, y Milón de Crotona, primer discípulo de Pitágoras y al cual se le atribuyen proezas gastronómicas como la de comerse un toro él solo. En este sentido, Detienne defiende que, en los sacrificios de animales, el olor de la carne asada une el inframundo con el cielo, pasando por la humana tierra; sin embargo, la quema de plantas sagradas de los sacrificios vegetarianos impulsa al ser humano exclusivamente hacia arriba, evitando los infiernos. Basa esta idea en el conocido mito que narra el engaño de Prometeo a Zeus y que explica que, en los sacrificios de animales, el aroma y los huesos son para los dioses, y las carnes, la piel y las vísceras, para los hombres. La misma lógica podría servir para analizar el pensamiento órfico, debido a que, si bien están atestiguadas costumbres y prescripciones vegetarianas, también existen mitos que describen el consumo desenfrenado de carne (a veces incluso humana) en ambientes dionisíacos.

\section{¿Cómo describieron el origen del mundo?}

"Todo era indistinto, en medio de una niebla tenebrosa". ${ }^{37}$ En el corpus de textos órficos se destacan dos temas: el origen del mundo y las descripciones e instrucciones para el más allá. Vale la pena hacer un breve comentario de ambos. En cuanto al primero, las versiones e interpretaciones varían. Además, con base en los textos que existen, se sospechan tradiciones prexistentes de las que no se tienen pruebas documentales. Como el propósito de este artículo no es presentar un listado detallado de los parecidos y diferencias entre las diferentes versiones, presentamos, más bien, unos pocos fragmentos que ilustran algunos

${ }^{36}$ M. Detienne, Los Jardines de Adonis, 1983, Akal, Madrid.

${ }^{37}$ Fr. 106. 
de sus temas principales y que sirven, con los ya reproducidos, para dar una pertinente panorámica general que, si bien no serviría para resumir todos los textos órficos, sí que serviría para delinear cómo se desplegó el cosmos según la mayoría de ellos.

(II) Orfeo es el primero que dice que en el principio hubo un Caos sempiterno, intenso, ingénito, del que todas las cosas se hicieron. Dijo, con razón, que este Caos no eran tinieblas, ni luz, ni húmedo ni seco, ni caliente ni frío, sino todo junto a la vez y que siempre permaneció único $\mathrm{y} \sin$ forma. ${ }^{38}$

El caos sin forma, la noche oscura, el barro resbaladizo, el agua mezclada con tierra... reinaban en el origen de los tiempos. Allí, en la etérea matriz primigenia, surgió el Tiempo.

Y Hesíodo dice que Amor nace de Caos, pero en las obras atribuidas a Orfeo, se dice de Tiempo: Y Tiempo engendró a Eros, y a los vientos todos. ${ }^{39}$

La Teogonía órfica transmitida por Jerónimo y Helánico [...] dice así: desde el principio hubo agua y la materia de la que se cuajó la tierra, siendo éstos los principios que suponen los primeros [...] El principio único anterior a los dos lo pasa en silencio, pues el hecho mismo de no decir nada de él muestra su carácter inefable. ${ }^{40}$

Tiempo engendró el huevo cósmico, y del huevo cósmico nació la Luz (Fanes), el Amor (Eros) o el niño sagrado (Ericepeo), que son los distintos nombres que se le dan al dios primogénito y ordenador del mundo; porque el amor es luz, la luz, amor, y el niño santo, símbolo de ambos.

(I) El tercer principio después de estos dos se originó de ellos, digo, del agua y de la tierra, y fue un dragón dotado por naturaleza de cabezas añadidas, una de toro y otra de león, y en medio de ellas el rostro de un dios. Sobre sus hombros tenía alas y se llamaba Tiempo desconocedor de la Vejez y Heracles. ${ }^{41}$

\footnotetext{
${ }^{38}$ Fr. 104.

${ }^{39}$ Fr. 360.

${ }^{40} \mathrm{Fr} .75$.

${ }^{41}$ Fr. 76.
} 
En otro lugar hemos tratado de responder al misterioso nombre que los órficos le daban a Tiempo: Heracles. ${ }^{42}$ La convergencia de ellos con el dios sol, e incluso con Jesucristo, podría, quizás, inferirse atendiendo al simbolismo y a la astronomía. En el éter cósmico, Tiempo pone un huevo.

La sustancia en su totalidad, movida por el tiempo, concibió el cielo, esférico y que todo lo abarca, como un huevo. Éste, al principio, estaba lleno de una médula fecunda, capaz de dar a luz elementos y colores de todas clases, aunque esta apariencia abigarrada se producía a partir de una sola sustancia y de un solo color. En efecto, de igual modo que en la generación del pavo real el huevo no muestra sino un solo color, pero en potencia contiene en sí mismo los innúmeros colores que va a tener cuando llegue a su perfección, así también el huevo animado nacido de la materia indefinida, por el impulso de la materia subyacente y en continuo flujo hace aparecer variados cambios [...] Pues bien, el huevo primigenio calentado poco a poco se rompe por el animal que hay dentro de él. ${ }^{43}$

Del huevo sale la luz del mundo, Fanes, el primer dios, el primero en tener cetro, el primero en poner orden: "Pues Fanes se sienta en el interior del santuario de la Noche"; 44 "En efecto, Fanes fue el primero que construye el cetro"; 45 "Con él en su mano, asignó a dioses y mortales el mundo ordenado, sobre el que reinó el primero el muy celebrado Ericepeo". ${ }^{46}$

El huevo cósmico, que tanto juego le da a Aristófanes en Las Aves, es una especie de arca de Noé que contiene todo lo que luego germinará en el mundo. En Grecia, este motivo no es exclusivo del orfismo. Helena, por ejemplo, nació de un huevo. De algún modo, ella misma es el huevo que contenía a todo su pueblo: por un lado, su historia de amor es el mito fundador de la Grecia homérica y clásica; por el otro, su nombre, Helena, contiene el de todos los griegos (los helenos). ${ }^{47}$ Helena de Troya es, por tanto, Grecia en potencia.

${ }^{42}$ J. Martínez Villarroya, "Dioniso, el zodíaco y el grial. Interpretación simbólica de ciertos pasajes órficos", Ex Novo, Revista d'Història i Humanitats, núm. 4, diciembre de 2007, pp. 59-81.

${ }^{43}$ Fr. 120.

${ }^{44}$ Fr. 164.

${ }^{45}$ Fr. 165.

${ }^{46}$ Fr. 167.

${ }^{47}$ Martínez Villarroya, J., Las Estructuras Antropológicas del Imaginario Órfico, el Cetro, la Crátera y el Niño, tesis de doctorado, 2008, Universidad de Barcelona, ediciones electróni- 


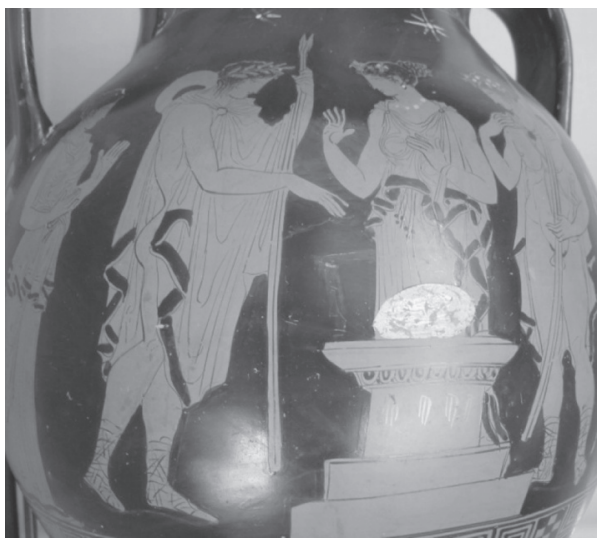

El huevo de Helena en un altar. Los dos personajes principales probablemente son Leda y Tíndaro.

Siglo V a. C, Museo de Nápoles. Fotografía cedida por la doctora Ada Cortés, a quien le agradezco su colaboración.

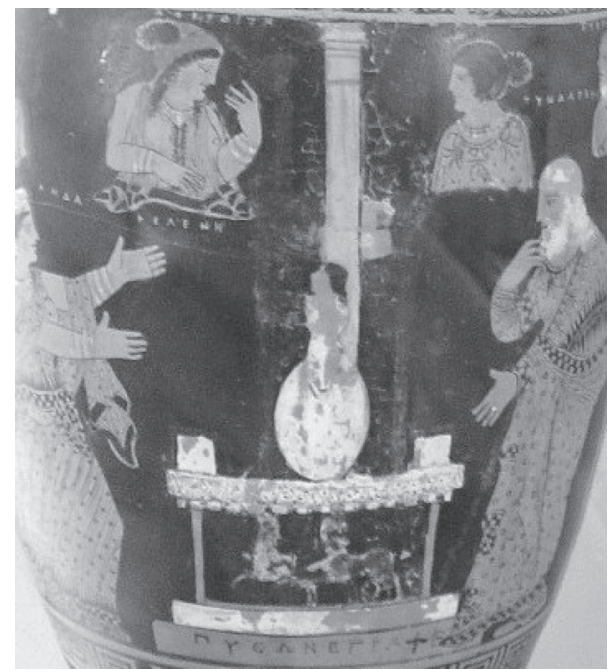

Helena saliendo del huevo. Pintura de Python (aprox. 350-340 a. C.). Se encontró en el corredor de la tumba 24 de Andriuolo.

Pastum, antigua Poseidonia, museo de sitio. Fotografía cedida por la doctora Ada Cortés, a quien le agradezco su colaboración.

cas de la UB, http://www.tesisenxarxa.net/TDX-0523108-105649/, pp.325-355, recuperado el 7 de diciembre de 2012. 
Algunas versiones órficas del inicio del mundo no hablan del huevo (en concreto, la del Papiro Derveni y la de Eudemo). Sin embargo, la mayoría de ellas hablan de que, tras esta primera etapa en la que nace la luz (el germen del mundo), el Cielo y la Tierra se separan y, de ellos, nace una nueva generación de dioses. Estos hijos del padre Cielo y de la madre Tierra son entidades antiquísimas y monstruosas, por ejemplo, las Moiras o los centimanos, aunque no todos los textos nombran del mismo modo a estos personajes. Avisado por un oráculo de que uno de sus hijos iba a desposeerlo del trono, Cielo los arroja a todos al Tártaro (la más profunda sima del mundo). Entonces, enojada, la madre Tierra decide vengarse y da a luz a los titanes, también hijos del Cielo estrellado. Crono, ${ }^{48}$ que no debe confundirse con Tiempo, le corta el pene a su padre y lo destrona lanzándolo fuera del carro. Sin embargo, el reinado del propio Crono acaba de forma parecida a como acabó el de su padre: Zeus, el hijo más joven de Crono, arroja a su vez a su padre y a todos los titanes al Tártaro. Entonces, Zeus reordena el mundo y, según algunas versiones, lo hace ingiriendo a Fanes, es decir, "iluminado" ${ }_{4} 9$

Para los órficos, a diferencia de la "religión olímpica", el cetro de los dioses cambió una vez más de mano. Según ellos, Zeus yació con su propia madre, Rea o Deméter, y, luego, con su propia hija, Perséfone. Con esta última tuvo a Dioniso, el dios regente y "tres veces nacido".

(I) (Sobre el triple nacimiento de Dioniso), el primero, el de su madre, el segundo, el del muslo, el tercero, cuando, tras haber sido despedazado por los Titanes, volvió a la vida después de que Rea recogiera los pedazos..$^{50}$

\section{¿Cómo describieron el alma?}

Cuando el iniciado órfico descendía a los infiernos, lo hacía acompañado de un "mapa" del más allá y una clave - escritos en papiro u oro-que le abrirían las puertas de la salvación.

${ }^{48}$ Seguimos la traducción de Bernabé: Kronos es Crono y Xronos es Tiempo.

${ }^{49}$ Fr. 85. Porque Fanes es la luz.

${ }^{50}$ Fr. 59. 
Encontrarás a la izquierda de la morada de Hades una fuente y cerca de ella un blanco y enhiesto ciprés, a esa fuente no te acerques en ningún caso. Encontrarás otra, de la que mana el agua fresca del lago de Memoria, delante de la cual están los guardianes, diles: "Soy hijo de la Tierra y del Cielo estrellado, pero mi estirpe es celeste y esto lo sabéis también vosotros, agonizo de sed y perezco, dadme prestamente del agua fresca que mana del lago de Memoria", y ellos te permitirán beber de la fuente divina y después reinarás junto con los demás héroes $[\ldots]$ este $[\ldots]$ a punto de morir $[\ldots]$ escrito $[\ldots]$ las tinieblas cubriendo todo alrededor $[\ldots] .^{51}$

Órficos y pitagóricos creían en la transmigración del alma.

Es lo que nos enseña la teología órfica $[\ldots]$ nos lo transmite claramente Orfeo cuando, después del mito del castigo de los Titanes y del nacimiento de los seres mortales, dice primero que las almas cambian de vida según determinados períodos y penetran a menudo unas en unos cuerpos y otras en otros: los mismos son padres e hijos en las casas, decorosas esposas, madres e hijas; nacen unos de otros con la mudanza de las generaciones. En efecto en estos versos nos transmite el cambio de residencia de unos cuerpos humanos en otros [...] pero luego hay también cambio de las almas humanas en otros animales, y eso nos lo enseña también Orfeo: pues el alma, mudada, según los ciclos del tiempo trasnmigra de hombres a unos y otros animales: unas veces vienes a ser caballo, [...] otras veces oveja, otras, ave de pavoroso aspecto, otras en cambio cuerpo canino y voz profunda, y estirpe de gélidas sierpes que se arrastra en la divina tierra. ${ }^{52}$

La idea de la reencarnación la encontramos también en filósofos antiguos, como por ejemplo Empédocles: "Que yo he sido antes un joven y una joven, un matorral y un pájaro, y un mudo pez del mar". ${ }^{53}$

${ }^{51} \mathrm{Fr} .476$ o Laminilla de Petelia, Los caminos de la muerte, Religión, rito e imágenes del paso al más allá en la Grecia antigua, 1995, Madrid, trad. de F. Díez de Velasco, biblioteca Virtual Miguel de Cervantes, http://www.cervantesvirtual.com/obra-visor/los-caminos-de-la-muertereligion-rito-e-iconografia-del-paso-al-mas-alla-en-la-grecia-antigua--0/html/00af14da82b2-11df-acc7-002185ce6064 50.html, recuperado el 8 de febrero de 2013.

${ }^{52}$ Fr. 338.

${ }^{53}$ Fr. 451 = Empédocles 31 B 117 D.K. 
Sin embargo, en determinado momento, el iniciado podía salirse del ciclo de las reencarnaciones. Hérodoto da noticias de ello.

Dicen los egipcios que quienes imperan en el mundo subterráneo son Deméter y Dioniso. También fueron los egipcios los primeros en enunciar esa doctrina de que el alma del hombre es inmortal y que, a la muerte del cuerpo, penetra en otro ser que se torna siempre vivo. Una vez que ha recorrido todos los seres terrestres, marinos y alados, vuelve a entrar en el cuerpo de un hombre que está a punto de nacer y cumple este ciclo por tres mil años. Hay algunos griegos, unos antes, otros después, que siguieron esta teoría, cuyos nombres yo no escribo, aunque los conozco. ${ }^{54}$

El iniciado órfico pretendía, precisamente, acortar el largo periplo al que su alma estaba condenada. Para ello, disponía de las fórmulas mencionadas (y otras parecidas), que debía recitar ante los dioses del infierno. Algunas de estas fórmulas son, con bastante probabilidad, anteriores a los textos propiamente órficos. Por ejemplo, en las laminillas de Pelina publicadas en 1987, tales fórmulas -según Bernabé- no están en verso como el resto del texto, sino en una especie de prosa rítmica.

Vengo de entre puros, pura, reina de los seres subterráneos, Eucles, Eubúleo y demás dioses inmortales. Pues también yo me precio de pertenecer a vuestra estirpe bienaventurada, pero me sometió el hado y el que hiere desde los astros con el rayo. Salí volando del penoso ciclo de profundo pesar, me lancé con ágiles pies a por la ansiada corona y me sumí bajo el regazo de mi señora, la reina subterránea: "Venturoso y afortunado, dios serás, de mortal que eras". Cabrito en la leche caí. ${ }^{55}$

En este artículo, eminentemente introductorio, hemos priorizado la exposición sobre la interpretación: como establece Aristóteles en la Retórica, antes de la argumentación debe exponerse la narración. Ahora bien, hecha la concisa panorámica sobre las fuentes órficas, sus interpretaciones más relevantes y su contenido, y a modo de conclusión, nos

${ }^{54}$ Fr. 423 = Herodoto II, 123.

${ }^{55}$ Fr. 488. 
permitimos añadir un par de esbozos de interpretaciones que pretendemos desarrollar en escritos posteriores. Por un lado, sospechamos que la posibilidad de escapar del ciclo de las reencarnaciones se fundamentaba en el décalage que los antiguos percibían tanto en las leyes de la astronomía como en las de la música. ${ }^{56}$ En realidad, el décalage estaba en la estructura misma del cosmos, y en lugar de ser imperfección era la condición de salvación. Hay suficientes datos para tal sospecha. Órficos y pitagóricos comparten muchas creencias, especialmente en torno a la música. Según la tradición, Pitágoras “descubrió” los siete planetas y las siete notas musicales (los primeros superpuestos a los doce signos zodiacales y las segundas, a los doce semitonos). El hecho de que estos dos descubrimientos, junto con una férrea defensa de la inmortalidad del alma, se le atribuyan a Pitágoras hace de estos tres campos (astronomía, música y escatología) un solo indisociable. La música de las esferas evocada por Platón en diversos pasajes de sus obras y por Cicerón en el Sueño de Escipión podría servir también para entender cómo los órficos esperaban liberarse del ciclo de las reencarnaciones.

“QQué es esto? ¿Qué sonido es éste tan grandioso y suave y que llena mis oídos?" Respondió él -el Africano-: “Es el sonido que se produce por el impulso y movimiento de las órbitas, compuesto de intervalos desiguales, pero armonizados, y que, templando los tonos agudos con los graves, produce equilibradamente armonías varias. [...] la órbita superior del Cielo, aquella de las estrellas, cuyo giro es el más rápido, se mueve con un sonido agudo e intenso, y con el sonido más grave, en cambio, este inferior de la Luna, pues la Tierra, en el noveno lugar, permanece siempre en su sede, inmóvil, ocupando el lugar central de todo el mundo. Esas ocho órbitas, dos de las cuales son iguales, producen

${ }^{56} \mathrm{El}$ recorrido anual del sol entre las estrellas no dura exactamente lo mismo que su desplazamiento por la línea del horizonte en sus salidas y puestas anuales (por ello existen los años bisiestos); la llamada "espiral de quintas", basada en los armónicos naturales, produce un décalage insalvable entre octavas (A. Daniélou, Traité de musicologie comparé, 1959, París, Hermann, y J. Martínez Villarroya, Las Estructuras Antropológicas del Imaginario Órfico..., op. cit., http://www.tesisenxarxa.net/TDX-0523108-105649/, recuperado el 12 de febrero de 2013). 
siete sonidos distintos por sus intervalos, cuyo número siete es como la clave de todas las cosas. Imitando esto los hombres sabios en las cuerdas de la lira y en los modos del canto, se abrieron el camino para poder regresar a este lugar-la Vía Láctea-, lo mismo que otros que, con superior inteligencia, cultivaron en su vida humana los estudios divinos". ${ }^{57}$

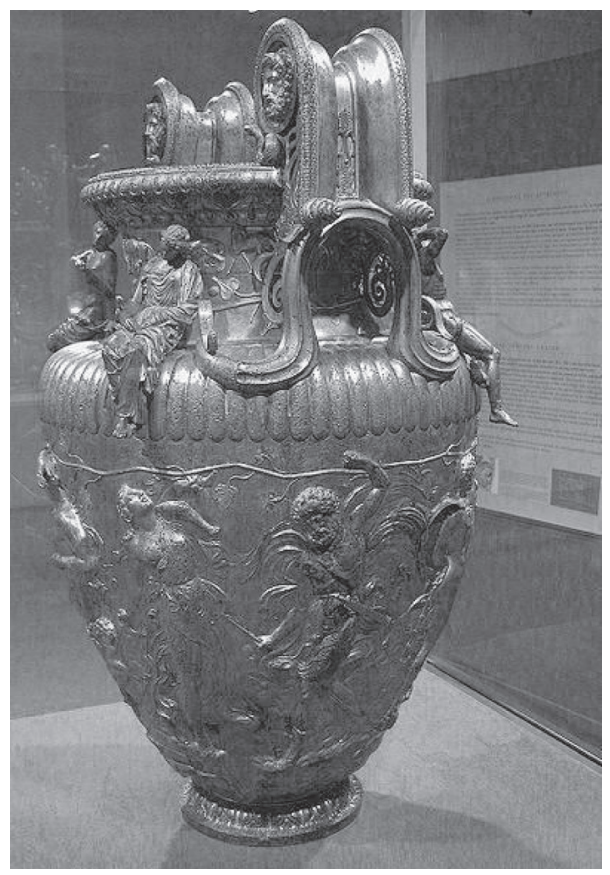

En el yacimiento en donde se encontró el Papiro Derveni se encontró también la espectacular Crátera de Derveni. (C) Michael Greenhalgh, http://rubens.anu.edu.au/raider5/greece/thessaloniki/museums/archaeological/metalwork/derveni_ krater/views/, recuperado el 12 de febrero de 2012.

En el Sueño de Escipión se destaca que el siete es la clave de todas las cosas y que los hombres sabios (los iniciados) son capaces de abrirse camino en el otro mundo con el canto y la lira, como hizo Orfeo. ¿Por qué es legítimo relacionar tales ideas con los órficos? Se sabe que existió un texto órfico llamado La Lira, y este instrumento está representado en algunos sarcófagos, lo que ha hecho sospechar que servía, entre los pitagó-

${ }^{57}$ M. T. Cicerón, Sobre la república, libro VI, 18 (1986, Madrid, Gredos, trad. de Álvaro d'Ors). 
ricos y los órficos, para indicar al alma su camino astral, ${ }^{58}$ como sugiere el texto de Cicerón y el propio mito de Orfeo.

Pero el alma, una vez liberada del ciclo de las reencarnaciones gracias a las grietas del orden cósmico, ¿dónde llega? A esta pregunta, respondemos con nuestro segundo esbozo de interpretación. El alma tiene su origen en el éter, porque "el éter es raíz de todas las cosas". ${ }^{59}$ Los antiguos situaban el éter más allá de la esfera de las estrellas. Por encima de la tierra, el agua, el aire y el fuego, en la parte más alejada del centro terrestre, estaba el éter. Por eso, "el alma penetra desde el universo exterior cuando se respira, arrastrada por los vientos". ${ }^{60}$ Nuestra segunda hipótesis es, en consecuencia, que al morir el alma, regresa al lugar de donde nació: regresa al útero materno, al sagrado éter. Esta hipótesis podría desarrollarse, también, a partir del Corpus Hermeticum que, sin duda, hereda bastantes ideas órficas:

Si bien el creador [...] repartió entre todos los hombres la razón, no hizo lo mismo con el pensamiento [...] Quiso que el pensamiento se asentara entre las almas como recompensa.

- ¿Y dónde lo emplazó, padre?

- Llenó con el pensamiento una gran crátera y la envió a este mundo acompañado de un heraldo que tenía la misión de proclamar a los corazones de los hombres estas palabras: "sumérgete en esta crátera tú que puedes hacerlo y tú que confías en que retornarás junto al que la ha enviado y sabes por qué has nacido". Aquellos que comprendieron la proclama y se sumergieron en el pensamiento, participaron del conocimiento y se convirtieron en hombres perfectos, "dotados de pensamiento". ${ }^{61}$

El fragmento no sólo contiene una reminiscencia de la arcaica fórmula órfica "Cabrito -o Toro o Carnero- en la leche caí", ${ }^{62}$ sino que

${ }^{58}$ F. Molina Moreno (dir. A. Bernabé), Orfeo y la mitología de la música, 1998, Madrid, tesis doctoral del departamento de filología griega y lingüística indoeuropea de la Universidad Complutense de Madrid, http:/eprints.ucm.es/tesis/19972000/H/3/H3066301.pdf, recuperado el 8 de febrero de 2013, pp. 528 ss.

${ }^{59}$ Fr. 116.

${ }^{60}$ Fr. 421.

${ }^{61}$ Corpus Hermeticum, IV, 4.

${ }^{62}$ Frr. 485-8. 
también recuerda el título de otro texto órfico, La Crátera,${ }^{63}$ probablemente consagrado al alma del mundo. Además, evoca algunos otros fragmentos: "Orfeo conoce también la crátera de Dioniso y dispone a otros muchos en torno a la mesa del sol". ${ }^{64}$ Aunque las dos hipótesis aquí expuestas pueden parecer arriesgadas, nos ofrecen más luz que sombras para interpretar los textos órficos y, en general, el pensamiento griego. Si los órficos cuestionaron la mortalidad del alma, contra el pensamiento imperante en su época, lo hicieron porque cuestionaron, en general, la estructura misma del cosmos griego.

${ }^{63}$ OF 241.

${ }^{64}$ Fr. 335. 
CITAM Derechos Reservados.

La reproducción total o parcial de este artículo se podrá hacer si el ITAM otorga la autorización previamente por escrito. 